\title{
OUTCOME OF OPEN HEART SURGERY IN PATIENTS WITH AGE ABOVE 75 YEARS.
}

1. MBBS, FCPS (Surgery), FCPS (Cardiac Surgery)

Associate Professor Cardiac Surgery

Rawalpindi Institute of Cardiology, Rawalpindi.

2. MBBS, FCPS (Cardiac Surgery)

Assistant Professor of Cardiac Surgery

Cardiac Center BahawalpurQuid-e-Azam Medical College.

3. MBBS, FCPS (Cardiac Surgery)

Associate Professor Cardiac Surgery

CPE Institute of Cardiology, Multan

Correspondence Address:

Dr. Muhammad Zubair Ahmad Ansari

Assistant Professor of Cardiac Surgery

Cardiac Center Bahawalpur-

Quid-E-Azam Medical College.

insar_78@hotmail.com

Article received on:

09/04/2020

Accepted for publication:

08/06/2020

\begin{abstract}
Muhammad Mujtaba Ali Siddiqui' ${ }^{1}$, Muhammad Zubair Ahmad Ansari², Abdul Ghaffer ${ }^{3}$
\end{abstract}
\begin{abstract}
Objectives: Open heart surgery is considered as high risk procedure in elderly patients. We study the operative outcomes of open heart surgery in patients of age above 75 years in geography of world where life expectancy is around 67 years. Study Design: Retrospective Study. Setting: Research of Rawalpindi Institute of Cardiology (RIC). Periods: From January 2014 to December 2018. Material \& Methods: Demographic and baseline characteristics of patients were retrieved from cardiac surgery database (cascade, Lahore) of RIC. For all patients who underwent open heart surgery and had age above 75 years. Operative mortality, neurological outcome, low cardiac output state(LCOS), peri-operative myocardial infarction, postop.erative atrial fibrillation (POAF), acute kidney injury (AKI), chest reopening, ICU stay, hospital stay and 1-year survival etc. Are analyzed from retrieved data. Results: Operative mortality is $5.71 \%$, type II neurological deficit is $16.42 \%$ and POAF is $25 \%$. Incidence of peri-operative $\mathrm{MI}$, LCOS, AKI and chest reopening etc is low along with acceptable ICU stay and hospital stay durations. 1-years survival is $95.46 \%$. Conclusion: open heart surgery can be offered to patients with age above 75 years with low operative mortality and morbidity except with relatively higher incidence of Type-II neurological deficit and POAF. 1-years survival is impressive with figures of $95.46 \%$.
\end{abstract}

Key words: $\quad$ CABG, Operative Mortality, Open Heart Surgery, Type II Neurological Deficit.

Article Citation: Siddiqui MMA, Ansari MZA, Ghaffer A. Outcome of open heart surgery in patients with age above 75 years. Professional Med J 2020; 27(7):15211526. DOI: 10.29309/TPMJ/2020.27.07.4776

\section{INTRODUCTION}

As the median age of population is increasing, the proportion of elderly patients who are potential candidates for cardiac surgery is increasing. ${ }^{1,2}$ These patients often have multiple co-morbidities and are frail. They have relatively different respiratory, cardiovascular and metabolic system physiology than younger population. ${ }^{3,4}$ The extent of surgery, general anesthesia, use of cardio-pulmonary bypass (CPB), admission to ICU, hemodynamic instability all may affect the outcome of old patients when compared to younger patients. Hence the most appropriate treatment of this sub set of patients has never been determined and left mainly to the physician's clinical decision. Over the last two decades there has been extra ordinary reduction in mortality rate in patients undergoing cardiac surgery despite the fact that patients referred for cardiac surgery are older, more sick, have complex and advanced disease. This is mainly due to development in technology, evolution of knowledge, improved surgical techniques and better ICU care. ${ }^{5}$

Life expectancy of Pakistani population is 67.33 years in 2020 and it have increased $0.23 \%$ per years in years 2019 and 2018. ${ }^{6}$ The purpose of our study is to know that is it worthy to offer open heart surgery in patient population who already have survived more than 6-8 years of their expected life. Measuring the operative mortality, frequency of complication and post-procedure survival is the best objective parameters to answer the question. Aim for our study is to analyze the pattern of surgical procedures performed \& outcomes in elderly patients with above 75 years.

\section{MATERIAL \& METHODS}

Ethical approval for study is taken from institutional review board and ethical committee for research of 
Rawalpindi institute of cardiology (RIC). Electronic cardiac surgery database (cascade Lahore) was utilized to retrieve all the information related to research projected retrospectively from January 2014 to December 2018. Demographic variable and other baseline patient characteristic were noted i.e. Age, gender, angina class (CCS, I-IV), NYHA class(I-IV), diabetes mellitus, hypertension, smoking history, carotid artery disease of $50 \%$ or more, ejection fraction (EF), preoperative serum creatinine levels $(\mathrm{mg} / \mathrm{dl})$, weight $(\mathrm{kg})$, height $(\mathrm{cm})$, body surface area (BSA-cm2), body mass index (BMI), preoperative intra-aortic balloon pump insertion (IABP). Operative and post-operative information including aortic cross clamp time (min), total cardiopulmonary bypass time (CPB-mins), post-operative ventilation time, use of intravenous inotropic support (hrs), and endotracheal re-intubation is recorded from retrieved data. Outcome variable includes operative mortality, ICU stay (hrs), hospital stay (days), neurological deficit (type I or type II), low cardiac output syndrome, sepsis, postoperative atrial fibrillation, renal failure and chest reopening etc are recorded.

Following definition of outcome variables use for the study.

Peri-operative myocardial infarction (MI): is defined as raised cardiac bio-markers (preferably troponin) with at least one value above the 99th percentile of upper reference limit (URL) or new left bundle branch block (LBBB), new $Q$ waves in ECG within in $48 \mathrm{~h}$ of surgery.

Low cardiac output syndrome (LCOS): systolic blood pressure < 90mmhg with signs of end organ hypo perfusion (low urine output, lactic acidosis) with impaired cardiac function.

Acute kidney injury (AKI): $50 \%$ to $100 \%$ increase in baseline serum creatinine value.

Post-op atrial fibrillation (POAF): abrupt de novo on set of AF requiring either pharmacological or electrical cardio version with no previous AF.

Type-I neurological damage: brain damage that is limited to focal area of brain with clinical sign and symptoms and is detectable with CT-scan of brain.

Type-II neurological damage: new deterioration in intellectual function, confusion, agitation, disorientation, memory deficit or a non-metabolic seizure without evidence of focal injury.

Operative mortality is defined as death due to any cause within 30 days of surgery.

Data analysis is performed with Microsoft excel 2016 and SPSS version 2018. Mean and standard deviation of mean was measure for numeric variable and frequency for the categorical variable.

\section{RESULTS}

Total 140 patient were found who had age more than 75 years of age and underwent open heart surgery from January 2014 to December 2018. 130 patients underwent isolated coronary artery bypass grafting (CABG) while 10 patients underwent combine surgical procedure $(C A B G+A V R, \quad C A B G+$ carotid endarterectomy, $\mathrm{CABG}+\mathrm{MVR}$, DVR OR CABG + ASD repair). Table-I showed the mean, standard deviation of mean and frequency of numeric and categorical data for demographic and baseline characteristics of study population $(n=140)$ who underwent conventional CABG for coronary artery disease (CAD) with American heart association/ American college of cardiology (AHA/ACC) class I indication or other combine cardiac surgery procedure. All those patient underwent elective surgery.

Operative information's showed that the mean aortic cross clamp time is $62.78 \pm 28.87 \mathrm{~min}$ and total CPB time is $97.65 \pm 34.75$ in patient who underwent open heart surgery. Their postoperative elective ventilation time is $11.33 \pm$ $21.34 \mathrm{~min}$, duration of intravenous use is 28.19 \pm 24.11 while incidence of endotracheal reintubation is $3.57 \%$. Wide range of standard deviation value for post-operative ventilation hour and use of intravenous inotropes showed that few patient underwent prolong ventilation due to neurological deficit or due to low cardiac output 
state respectively.

\begin{tabular}{|c|c|}
\hline Variable & $\begin{array}{l}\text { Mean \& Standard } \\
\text { Deviation or } \\
\text { Frequency }\end{array}$ \\
\hline Age & $77.71+2.86$ \\
\hline $\begin{array}{l}\text { Gender } \\
\text { Female } \\
\text { Male }\end{array}$ & $\begin{array}{l}14.28 \%(n=20) \\
85.71 \%(n=120)\end{array}$ \\
\hline COPD & $16 \%(n=23)$ \\
\hline Hypertension & $45 \%(n=63 \%)$ \\
\hline Diabetes mellitus & $27.85 \%(n=39)$ \\
\hline Smoking & $18.57 \%(n=26)$ \\
\hline $\begin{array}{l}\text { Carotid artery disease of } 50 \% \text { or } \\
\text { more narrowing }\end{array}$ & $3.57 \%(n=5)$ \\
\hline $\begin{array}{l}\text { Ccs Class } \\
\text { I } \\
\text { II } \\
\text { III } \\
\text { IV }\end{array}$ & $\begin{array}{l}55.71 \%(n=78) \\
26.42 \%(n=37) \\
17.85 \%(n=25) \\
0 \%\end{array}$ \\
\hline $\begin{array}{l}\text { Nyha class } \\
\text { I } \\
\text { II } \\
\text { III } \\
\text { IV }\end{array}$ & $\begin{array}{l}22.86 \%(n=32) \\
62.85 \%(n=88) \\
14.28 \%(n=20) \\
0 \%\end{array}$ \\
\hline Weight & $69.43 \pm 11.65$ \\
\hline Height & $164.20 \pm 8.17$ \\
\hline BSA & $1.77 \pm 0.16$ \\
\hline BMI & $25.88 \pm 4.83$ \\
\hline $\mathrm{EF}(\%)$ & $50.43 \% \pm 9.24$ \\
\hline Prior $\mathrm{PCl}$ & $1.42 \%(n=2)$ \\
\hline Serum creatinine levels (mg/dl) & $0.90 \pm 0.22$ \\
\hline Pre-operative IABP & $0.71 \%(n=1)$ \\
\hline
\end{tabular}

Postoperative outcome of population of age above 75 years who underwent conventional CABG and other open heart surgical procedures revealed that the postoperative ICU stay was $55.43 \pm$ 28.27 hrs. Type I neurological deficit was $3.57 \%$ $(n=5)$ and all those patient who developed type I neurological deficit face the in-hospital mortality. It was interesting that 2 patient underwent CABG \pm carotid endarterectomy, none of those attained type-I neurological deficit. CT-scan of those patients showed massive disabling stroke and most of those never showed good sensorium before eventual outcome. Incidence of type-II neurological deficit was $16.42 \%$ which include either postoperative confusional state, change of personality, dementia etc. Most of these patient recovered eventually and discharged home. $5.71 \%(n=8)$ developed peri-operative MI and $4.28 \%(n=6)$ patient developed early postoperative low cardiac output syndrome. 2 out of these patient faced in-hospital mortality. Incidence of postoperative atrial fibrillation (POAF), sepsis, renal failure and mediastinal re-exploration were $25 \%, 3.57 \%, 5 \%$ and $8.57 \%$ respectively as show in table-III. One of the most concerned outcome in this age group population is operative mortality and that was $5.71 \%(n=8)$. Overall hospital stay is $7.08 \pm 2.11$ days. One of the most surprise finding was the outcome of combine procedure patients i.e. CABG plus MVR, CABG PLUS AVR, CABG plus ASD closure etc. These patients often own complex pathophysiology and co-morbidities, although there number was low in entire population but none of those face operative mortality. Clinical follow up showed that 1-year survival among 132 patients after hospital discharge was $95.46 \%$.

\begin{tabular}{|l|l|}
\hline \multicolumn{1}{|c|}{ Variable } & \multicolumn{1}{|c|}{$\begin{array}{c}\text { Mean\& standard } \\
\text { deviation or } \\
\text { frequency }\end{array}$} \\
\hline $\begin{array}{l}\text { Operative procedure } \\
\text { Isolated CABG } \\
\text { CABG + MVR } \\
\text { CABG + AVR } \\
\text { DVR } \\
\text { CABG + ASD repair } \\
\text { CABG + CA endarterectomy }\end{array}$ & $\begin{array}{l}130(92 \%) \\
3(2.1 \%) \\
3(2.1 \%) \\
1(0.71 \%) \\
1(0.71 \%)\end{array}$ \\
\hline Aortic cross clamp time (min) & $62.68 \pm 28.87$ \\
\hline CPB time (min) & $97.65 \pm 34.75$ \\
\hline Ventilation time (hrs) & $7.51 \pm 7.50$ \\
\hline Endotacheal re-intubation & $3.5 \%(\mathrm{n}=5)$ \\
\hline Inotropic use (hrs) & $28.19 \pm 24.11$ \\
\hline Table-II. Operative, intra-operative and post-operative \\
data.
\end{tabular}




\begin{tabular}{|l|l|}
\hline Operative mortality & $5.71 \%(n=8)$ \\
\hline ICU stay (hrs) & $55.43 \pm 28.27$ \\
\hline Hospital stay (days) & $7.08 \pm 2.11$ \\
\hline $\begin{array}{l}\text { Neurological complications } \\
\text { Type I } \\
\text { Type II }\end{array}$ & $\begin{array}{l}3.57 \%(n=5) \\
16.42 \%(n=23)\end{array}$ \\
\hline Peri-operative MI & $5.71 \%(n=8)$ \\
\hline Low cardiac output state & $4.28 \%(n=6)$ \\
\hline Sepsis & $3.57 \%(n=5)$ \\
\hline Atrial fibrillation & $25 \%(n=35)$ \\
\hline Acute kidney injury (AKI) & $5 \%(n=7)$ \\
\hline Chest reopening for bleeding & $8.57 \%(n=12)$ \\
\hline 1-years survival & $95.46 \%(n=128)$ \\
\hline \multicolumn{2}{|c|}{ Table-III. Outcomes of open heart surgery in } \\
patient with age above 75 years.
\end{tabular}

\section{DISCUSSION}

Atmany time, geriatric population of cardiovascular diseases are managed conservatively. Bad prognosis, frailty and less than optimal outcome are major compelling factors for medical therapy. But it is not infrequent that disease severity and clinical symptomatology make invasive procedure inevitable. In recent armamentarium of cardiology and cardiac surgery, rapidly expanding catheter based procedures are producing promising results and earning procedural indications. But these procedure like percutaneous coronary intervention $(\mathrm{PCl})$, transcutaneous aortic valve implantation (TAVI), mitraclip etc. Are either not available widely or not the best choice. Thus surgery becomes only viable option for those patients. Geriatric population is consider as high risk group in cardiac surgery because this population own organ physiology different from younger population in addition to constellation of bad prognostic factor like cerebrovascular disease, LV dysfunction, DM, COPD, renal impairment and peripheral arterial disease.4,7,8 these frail patients are vulnerable and show decreased resistance to physiological stress. Data from recent two decade showed promising operative results in this high risk population with acceptable mortality and low postoperative morbidities.9,10,11 Reported mortality has fallen from $15.7-24 \%$ to $3.2-7.1 \%$ with 5 -years survival up to $65 \% .12,13,14,15$ Possible explanation of these impressive results include better preoperative optimization, improved surgical strategies and postoperative standards of care. In our study population, we experience the same impressive results of current era with overall mortality of $5.71 \%$ and 1-year survival of $95.46 \%$ who discharged home after successful surgery.

The major proportion of our study population underwent CABG. We performed conventional CABG and combine procedure with carotid endarterectomy in few patients. Most of published data do not show any difference in operative outcomes with conventional CABG vs OPCAB in old age population.16,17,18,19 Few published studies, however, had shown that off-pump coronary artery bypass (OPCAB) strategy provide better early surgical outcome profile particular with respect to type II neurological deficit.20 High incidence of type II neurological defect was faced by our population as we performed conventional CABG in our study population. In future, we have plan to switch our surgical strategy from conventional CABG to OPCAB whenever possible to reduce incidence of type II neurological defects. We performed combined surgical procedure like $\mathrm{CABG}+\mathrm{AVR}$ and $\mathrm{CABG}+\mathrm{MVR}$ as well in our series although the numbers were low and we have much less to emphasize about operative outcomes. These patients own higher operative risk than isolated CABG.21 Lorusso et al had demonstrated that MV replacement appears to show better surgical outcome when compared to complex, challenging and time consuming mitral valve repair.22 Furthermore MVR do not compromise long term outcome in elder patients in term of repair vs replacement strategy.23 So we opted the same strategy for our surgical practice for combine mitral valve and myocardial revascularization surgery. 3 of our patients underwent combine aortic valve replacement and $\mathrm{CABG}$ and recovered smoothly but we are optimistic that TAVR plus $\mathrm{PCl}$ would have been a much less invasive procedure with excellent outcome particularly in patient with age above 75 years of age if expertise is available.

In nutshell, cardiac surgery in population above 75 years of age can be performed with acceptable 
operative mortality and morbidity except with relatively higher incidence of type II neurological defect and POAF. Other operative complications like renal dysfunction, post-operative MI, sepsis, chest reopening, ICU stay, hospital stay etc. are low in incidence. 1- years survival is also impressive in this population.

\section{CONCLUSION}

Open heart surgery can be offered to patients with age above 75 years with low operative mortality and morbidity except with higher incidence of type II neurological deficit and POAF. 1- years survival is impressive with figures of $95.46 \%$.

Copyright@ 08 June, 2020.

\section{REFERENCES}

1. National center for health statistics. Vital statistics of the united states us government printing office. Vol. 2. Washington, dc, USA: 1992

2. Friedrich I, Simm A, Kötting J, Thölen F, Fischer B, Silber Re. Cardiac surgery in the elderly patient. Deutsches ärzteblatt international. 2009; 106(25):416-422.

3. Oskvig RM. Special problems in the elderly. Chest. 1999; 115:158s-64. Doi: 10.1378/ chest.115.suppl_2.158s.

4. Pal R, Singh Sn, Chatterjee A, Saha M. Age-related changes in cardiovascular system, autonomic functions, and levels of bdnf of healthy active males: role of yogic practice. Age (dordr). 2014; 36(4):9683. Doi: 10.1007/s11357-014-9683-7.

5. Song Hk, Diggs Bs, Slater Ms, Guyton Sw, Ungerleider $\mathrm{Rm}$, Welke Kf. Improved quality and costeffectiveness of coronary artery bypass grafting in the united states from 1988-2005. J thorac cardiovasc surg. 2009; 137:65-9. Doi: 10.1016/j.jtcvs.2008.09.053.]

6. Macro trends. Pakistan life expectancy 1950-2020. Available from: https://www.macrotrends.net/countties/ pak/pakistan/life expectancy[ accessed 3 may 2020

7. Trummer g, Beyersdorf $\mathrm{f}$. Heart surgery in the elderly. Deutsche medizinische wochenschrift. 2005; 130(12):731-734.

8. Lee DH, Buth KJ, Martin B-J, YIP AM, Hirsch GM. Frail patients are at increased risk for mortality and prolonged institutional care after cardiac surgery. Circulation. 2010; 121(8):973-978.]
9. Wk F, Schaff Hv, O'brian Pc, Orszulak Ta, Naessens $\mathrm{Jm}$, Tajik Aj. Cardiac outcome in the octogenarian: Perioperative outcome and clinical follow-up. J am coll cardiol. 1991; 18(1):29-35. Doi: 10.1016/s07351097(10)80212-8.

10. Nissinen J, Wistbacka J-O, Loponen P, et al. Coronary artery bypass surgery in octogenarians: Long-term outcome can be better than expected. Annals of thoracic surgery. 2010; 89(4):1119-1124.

11. Filsoufi F, Rahmanian PB, Castillo JG, Chikwe J, Silvay $G$, Adams DH. Results and predictors of early and late outcomes of coronary artery bypass graft surgery in octogenarians. Journal of cardiothoracic and vascular anesthesia. 2007; 21(6):784-792.

12. Nicolini F, Molardi A, Verdichizzo D, Et Al. Coronary artery surgery in octogenarians: Evolving strategies for the improvement in early and late results. Heart and vessels. 2012; 27:559-567.

13. Edmunds LH, Stephenson LW, EDIE RN, Ratcliffe MB. Open-heart surgery in octogenarians. N engl j med. 1988; 319:131-6. Doi: 10.1056/ nejm198807213190302.

14. Maganti M, Rao V, Brister S, Ivanov J. Decreasing mortality for coronary artery bypass surgery in octogenarians. Canadian journal of cardiology. 2009; 25(2):e32-e35.]

15. Zingone B, Gatti G, Rauber E, Et Al. Early and late outcomes of cardiac surgery in octogenerians. Annals of thoracic surgery. 2009; 87(1):71-78.

16. Hlatky Ma, Boothroyd Db, Bravata Dm, et al. Coronary artery bypass surgery compared with percutaneous coronary interventions for multivessel disease: A collaborative analysis of individual patient data from ten randomised trials. The lancet. 2009; 373(9670):1190-1197.

17. Saleh Hz, Shaw M, Fabri BM, Chalmers JAC. Does avoidance of cardiopulmonary bypass confer any benefits in octogenarians undergoing coronary surgery? Interactive cardiovascular and thoracic surgery. 2011; 12(3):435-439.

18. Lapar Dj, Bhamidipati Cm, Reece Tb, Cleveland Jc, Kron II, Ailawadi G. Is off-pump coronary artery bypass grafting superior to conventional bypass in octogenarians? Journal of thoracic and cardiovascular surgery. 2011; 141(1):81-90.

19. Jensen Bø, Rasmussen Ls, Steinbrüchel da. Cognitive outcomes in elderly high-risk patients 1 year after off-pump versus on-pump coronary artery bypass grafting. A randomized trial. European journal of cardio-thoracic surgery. 2008; 34(5):1016-1021. 
20. Zangrillo A, Crescent G, Landoni G, Leoni A, Marino $\mathrm{G}$, Calabrò $\mathrm{Mg}$, et al. Off-pump coronary artery bypass grafting reduces postoperative neurologic complications compared to CPB. J cardiothorac vasc anesth. 2005; 19(2):193-6. Doi: 10.1053/j. jvca.2005.01.030

21. Biancari F, Schifano P, Pighi M, Vasques F, Juvonen T, Vinco G. Pooled estimates of immediate and late outcome of mitral valve surgery in octogenarians: A meta-analysis and meta-regression. $\mathrm{J}$ cardiothorac vasc anesth. 2013; 27(2):213-9. Doi: 10.1053/j. jvca.2012.11.007.
22. Lorusso R, Gelsomino S, Vizzardi E, et al. Mitral valve repair or replacement for ischemic mitral regurgitation? The Italian study on the treatment of ischemic mitral regurgitation (istimir) the journal of thoracic and cardiovascular surgery. 2013; 145(1):128-139.

23. Gillinov Am, Blackstone Eh, Nowicki Er, et al. Valve repair versus valve replacement for degenerative mitral valve disease. Journal of thoracic and cardiovascular surgery. 2008; 135(4):885-893.

\begin{tabular}{|c|c|c|c|}
\hline \multicolumn{3}{|c|}{ AUTHORSHIP AND CONTRIBUTION DECLARATION } \\
\hline Sr. \# & Author(s) Full Name & Contribution to the paper & Author(s) Signature \\
\hline 1 & M. Mujtaba Ali Siddiqui & 1st Author & \\
\hline 2 & M. Zubair Ahmad Ansari & 2nd Author & $\mid$ \\
3 & Abdul Ghaffer & 3rd Author & \\
\hline
\end{tabular}

